\title{
REGULATION ASPECT OF LEARNERS' LANGUAGE LEARNING STYLE IN DIFFERENTIATED ESP INSTRUCTION
}

\author{
Oksana Synekop \\ National Technical University of Ukraine "Igor Sikorskiy Kyiv Polytechnic Institute”, \\ Kyiv, Ukraine \\ oksana.synekop@gmail.com
}

\begin{abstract}
This study aims to investigate the issue of regulation aspect of learner's language learning style in differentiated instruction of English for Specific Purposes (ESP) at technical universities. In particular, we defined and characterised the self-regulation levels of information technology (IT) students; outlined recommendations for improvement of students' regulation while developing listening, speaking, reading and writing skills. To achieve that purpose we used mixed research methods in our study which involved 382 thirdand fourth-year IT students. To collect the data, "Self-regulation Style of Learning Activities" questionnaire developed by Morosanova and Bondarenko (2015), was used. As shown by the survey, most learners had a medium level of self-regulation, smaller number of students had a high level of self-regulation, and only some of them had a low level of self-regulation, which implies that students need to develop their regulation skill. Using the descriptors suggested by Morosanova and Bondarenko (2015), we defined students' self-regulation levels in ESP instruction. To enhance the level of self-regulation, share-regulation and coregulation in ESP learning the recommendations were given. In particular, since learning can be conducted individually, in pairs, teams and groups, various specifics of students' regulation in ESP study was reflected in checklists for self-regulation, socially shared regulation and co-regulation. For creating the checklists, the phases of Zimmerman (2003) model and cognition, metacognition, motivation, emotion, and behaviour regulation areas were used. Finally, recommendations were suggested to ESP teachers for improvement of learners' regulation while developing listening, speaking, reading and writing skills in differentiated ESP instruction.
\end{abstract}

Keywords: differentiated instruction; learning style; regulation aspect; English for specific purposes; IT-students.

\section{Introduction}

Training of qualified Information Technology (IT) specialists with foreign language proficiency level adequate for meeting professional needs is the primary task in teaching English for specific purposes (ESP) at Ukrainian technical universities. To ensure the effective ESP instruction of IT students the educational process should be focused on learners' individual features. This means that learners' differentiation in language learning style and English language proficiency levels should be considered in ESP instruction.

Learners' language learning style is a multi-aspect construct in which each aspect mirrors certain specifics of an individual and requires applying appropriate ESP teaching and learning techniques in the learning environment. Along with the prevalent cognitive aspect (Dörnyei, 2005, p. 124; Dörnyei \& Ryan, 2015, p. 112; Derkach, 2018; Saienko, 2017; Synekop, 2018) and motivational aspect (Guild and Garger, 1998), scholars and educational practitioners (Vermunt, 1998; Zimmerman \& Campillo, 2003; Nilson, 2013) also focus on the significance of regulation aspect in development of language skills. In this regard, regulation of learning allows learners to direct their processing of content material, and "is influenced by conceptions of learning and learning orientations" (Vermunt, 1998, p. 152).

Among the variety of terms used in this context, the most important ones are "self-regulation", "socially shared regulation" and "co-regulation" (Zimmerman, 2001; Hadwin, Järvelä, Miller, 2018, p. 83; Tezci et al., 2016; Mahmoodi, Kalantarib, \& Ghaslanic, 2014; Kaplan et al., 2017). Self-regulation is explained as "the degree to which learners are active participants in their own learning" (Dörnyei, 2005, p. 191) and are "proactive in their pursuit of language learning" (Macaro, 2001, p. 264). In contrast to self-regulation, socially shared regulation and co-regulation rely on the adjustment in groups. In our opinion, the principal difference in terminology is in that socially shared regulation focuses on the regulative interactive processes between peers in a group while co-regulation implies the group members' regulation processes during creating a certain product in a project. As a rule, co-regulation can involve the self-regulation and socially shared regulation. Thus, in our view, the key regulation is self-regulation which can exist independently or be connected with the other types of regulation. It is obvious that individual, pair, team and group learning imply various specifics in regulating the ESP teaching and learning processes.

While researching the regulatory aspect scientists point out that self-regulation learning encompasses cognitive, metacognitive, behavioural, motivational, emotional / affective and context areas (Zimmerman, 2001; Pintrich, 2000), improves competencies through defining goals of the task (Schunk \& Swartz, 1993); develops trajectories of skills and abilities (Hoyle \& Dent, 2018). The literature analysis shows that a wide

Synekop, O. (2020). Regulation aspect of learners' language learning style in differentiated esp instruction. Advanced Education, 15, 25-31. DOI: $10.20535 / 2410-8286.201978$ 
range of self-regulation (Zimmerman\& Campillo, 2003; Pintrich, 2000), socially shared regulation and coregulation (Hadwin, Järvelä \& Miller, 2018) models has been developed. In our opinion, the most rational model of self-regulation was created by Zimmerman (2003). It involves three interrelated and cyclic phases with corresponding sub-processes: forethought, performance and self-reflection phases (Zimmerman, 2003). In addition, the method of reflective writing, genre content questions, self-testing of recall and visual study tools are offered to foster self-regulation in reading, watching, and listening (Nilson, 2013, p. 26-36). Thiede and Bruin (2018) suggest writing summaries, generating keywords, completing diagrams, concept mapping, self-explanation, test expectancy to promote self-regulated learning in reading. However, in spite of a number of studies which focus on features of general regulation processes, regulation aspect of learners' language learning style in differentiated ESP instruction needs further study.

\section{Purpose}

In view of this, the aim of this paper is

1) to determine and characterise the self-regulation levels of the third- and fourth-year IT students;

2) to outline recommendations to ESP teachers for improvement of learners' regulation while developing listening, speaking, reading and writing skills in differentiated ESP instruction.

\section{Methods}

Research design

The study involved the use of "Self-regulation Style of Learning Activities" questionnaire by Morosanova and Bondarenko (2015). The quantitative research method was applied for defining the selfregulation levels of the IT students based on the mentioned questionnaire. The qualitative research method was used to analyse the description of self-regulation levels and interpret the self-regulation levels of the IT students in differentiated ESP instruction. Thus, the study was designed according to Creswell's (2014) "Explanatory Sequential Mixed Methods Design" model that involved quantitative data collection and analysis with the following qualitative data collection and analysis (p. 270).

\section{Participants}

In total, 382 third- and fourth-year IT students (11 academic groups), males and females, of the Institute of Physics and Technology and the Faculty of Informatics and Computer Science of National Technical University of Ukraine "Igor Sikorsky Kyiv Polytechnic Institute" took part in the survey during 2017-2019. The participants had different language learning styles and different language proficiency levels - from intermediate to advanced. All of them were volunteers, thus the number of students in the groups was different.

\section{Instruments and Procedures}

Two stages were outlined in the study. At the first stage, the questionnaire by Morosanova and Bondarenko (2015) was suggested for defining the self-regulation levels of the IT students. The questionnaire contained forty-five questions or statements about individual features of behaviour in the ESP learning activity. The questions composing the questionnaire were aimed to define students' individual strengths and weaknesses in planning, modelling, programming, assessment of results, flexibility, reliability (pp. 20-22). The learners had to choose one of four possible answers: "It is acceptable", "Perhaps, it is acceptable", "Perhaps, it is not acceptable", "It is not acceptable" and put a tick in the corresponding box on the answer sheet. The answers "It is acceptable" and "Perhaps, it is acceptable" correlate to "Yes"; "Perhaps, it is not acceptable" and "It is not acceptable" correspond to "No". The question numbers $02,03,04,06,08$, $10,11,13,14,16,17,19,23,25,27,29,31,33,34,35,39,42,43,44$ meant "yes" and implied "It is acceptable", "Perhaps, it is acceptable". The question numbers 01, 05, 07, 09, 12, 15, 18, 20, 21, 22, 24, 26, $28,30,32,36,37,38,40,41,45$ meant "no" and implied "Perhaps, it is not acceptable" and "It is not acceptable"). Three levels of self-regulation were determined - the low level ( $\leq 14$ points), the middle level (15-27 points) and the high level ( $\geq 28$ points). For each match of the learner's answer with the key of the questionnaire 1 point was awarded; for a mismatch no points were awarded. Completing the questionnaire took 20-25 minutes. At the second stage the obtained information was processed. Then the experience of the ESP teachers was analysed to outlining the recommendations to ESP teachers.

\section{Data Analysis}

In this study, data analysis was done in two stages. To answer the first research question, Morosanova and Bondarenko's (2015) questionnaire was used to determine the self-regulation levels of the IT students. To answer the second research question, the data about the teachers' experience obtained through interviews was analysed to define the recommendations for organising the differentiated ESP instruction. 


\section{Results}

Survey of 190 third-year IT students (Table 1) to determine the self-regulation levels showed that $25.78 \%$ of them had a high level, $66.32 \%$ - a medium level and $7.89 \%$ - a low level of self-regulation. It should be noted that the low level of self-regulation was not fixed in all groups.

Table 1. Self-regulation levels of the third-year IT students

\begin{tabular}{|l|c|c|c|c|}
\hline Groups & $\begin{array}{c}\text { Total } \\
\text { number of } \\
\text { students }\end{array}$ & $\begin{array}{c}\text { Number of } \\
\text { students } \\
\text { with high } \\
\text { level of self- } \\
\text { regulation }\end{array}$ & $\begin{array}{c}\text { Number of } \\
\text { students } \\
\text { with } \\
\text { medium } \\
\text { level of self- } \\
\text { regulation }\end{array}$ & $\begin{array}{c}\text { Number of } \\
\text { students } \\
\text { with low } \\
\text { level of } \\
\text { self- } \\
\text { regulation }\end{array}$ \\
\hline Group 1 & 26 & 5 & 18 & 3 \\
\hline Group 2 & 20 & 3 & 13 & 4 \\
\hline Group 3 & 27 & 10 & 17 & 0 \\
\hline Group 4 & 21 & 5 & 14 & 2 \\
\hline Group 5 & 11 & 2 & 9 & 0 \\
\hline Group 6 & 23 & 6 & 15 & 2 \\
\hline Group 7 & 6 & 4 & 1 & 1 \\
\hline Group 8 & 10 & 2 & 6 & 2 \\
\hline Group 9 & 15 & 3 & 11 & 1 \\
\hline Group 10 & 14 & 2 & 12 & 0 \\
\hline Group 11 & 17 & 7 & 10 & 0 \\
\hline Total: & 190 & 49 & 126 & 15 \\
\hline \% & & 25.78 & 66.32 & 7.89 \\
\hline
\end{tabular}

Survey of 192 fourth-year IT students (Table 2) for determining the self-regulation levels showed that a high level of self-regulation was fixed in $29.69 \%$, medium level - in $64.58 \%$ and low level - in $5.73 \%$ of respondents. In almost half of the groups, the low level of self-regulation was not fixed at all.

Table 2. Self-regulation levels of the fourth-year IT students

\begin{tabular}{|l|c|c|c|c|}
\hline Groups & $\begin{array}{c}\text { Total } \\
\text { number of } \\
\text { students }\end{array}$ & $\begin{array}{c}\text { Number of } \\
\text { students } \\
\text { with high } \\
\text { level of self- } \\
\text { regulation }\end{array}$ & $\begin{array}{c}\text { Number of } \\
\text { students } \\
\text { with } \\
\text { medium } \\
\text { level of self- } \\
\text { regulation }\end{array}$ & $\begin{array}{c}\text { Number of } \\
\text { students } \\
\text { with low } \\
\text { level of self- } \\
\text { regulation }\end{array}$ \\
\hline Group 1 & 15 & 4 & 10 & 1 \\
\hline Group 2 & 21 & 4 & 15 & 2 \\
\hline Group 3 & 24 & 9 & 15 & 0 \\
\hline Group 4 & 37 & 17 & 17 & 3 \\
\hline Group 5 & 21 & 7 & 14 & 0 \\
\hline Group 6 & 22 & 6 & 15 & 1 \\
\hline Group 7 & 14 & 3 & 11 & 0 \\
\hline Group 8 & 7 & 2 & 5 & 0 \\
\hline Group 9 & 8 & 4 & 4 & 0 \\
\hline Group 10 & 8 & 1 & 6 & 1 \\
\hline Group 11 & 15 & 0 & 12 & 3 \\
\hline Total: & 192 & 57 & 124 & 11 \\
\hline \% & & 29.69 & 64.58 & 5.73 \\
\hline
\end{tabular}

Comparison of the results presented in Tables 1 and 2 shows that the majority of the third- and fourthyear IT students have a medium level of self-regulation, approximately $1 / 3$ of the third- and fourth-year IT students have a high level of self-regulation. 


\section{Discussion}

Two questions arose during this study:

1. How can the high, medium and low levels of learners' self-regulation in differentiated ESP instruction be interpreted?

2. What recommendations can be given to foster learner's regulation while developing listening, speaking, reading and writing skills?

The levels of self-regulation of IT students defined with the use of the questionnaire by Morosanova and Bondarenko (2015) can be interpreted (Table 3) in the context of professional communication in differentiated ESP instruction. If the focus is made only on students' strengths and weaknesses in planning, programming, assessment of results, flexibility and independence, it is clear that IT students with a high level of self-regulation are able: to outline the learning goals with full responsibility and realise their potential through individual features of language learning style due to adequate English language proficiency level; to plan and model what and how to say; to create the professional text in English even if some communicative changes take place. The IT students with a medium level of self-regulation have some difficulties with determining goals and planning their professional communication in English, especially when changes in communicative situations need changes in tactics and strategies of communication. Such learners require certain facilitation of the teachers or other students. Unlike students of these two groups, IT students with a low level of self-regulation have significant problems in defining the learning goals, structuring an English text and assessing it and therefore need more help from the teachers and / or peers. Thus, defining the levels of self-regulation in IT students will allow ESP teachers to provide them with timely and adequate facilitation at different stages of training in the process of development of professional communicative competence.

Table 3. Interpretation of IT learners' self-regulation levels in professional communication based on Morosanova and Bondarenko's (2015) description

\begin{tabular}{|c|c|c|}
\hline High Level & Medium Level & Low Level \\
\hline $\begin{array}{l}\text { A student } \\
\text { - successfully determines and } \\
\text { understands the goals (using } \\
\text { their language learning style } \\
\text { at their language proficiency } \\
\text { level) in an ongoing } \\
\text { communicative situation as } \\
\text { well as in the "zone of } \\
\text { proximal development"; } \\
\text { - thinks over, plans and } \\
\text { identifies the program steps; } \\
\text { fully deploys the English } \\
\text { professionally oriented text in } \\
\text { oral or written forms; } \\
\text { - is capable of adequate self- } \\
\text { evaluation; is critical enough; } \\
\text { spots errors and corrects } \\
\text { them; } \\
\text { - quickly changes tactics and } \\
\text { strategies in the professional } \\
\text { communication if necessary; } \\
\text { - does not need any teacher's / } \\
\text { peers' support. }\end{array}$ & $\begin{array}{l}\text { A student } \\
\text { - determines and understands the } \\
\text { goals (using their language } \\
\text { learning style at their language } \\
\text { proficiency level) in an ongoing } \\
\text { communicative situation as well } \\
\text { as in the "zone of proximal } \\
\text { development" but has certain } \\
\text { difficulties; } \\
\text { - with some difficulties thinks over, } \\
\text { plans and identifies the program } \\
\text { steps; partially deploys the } \\
\text { English professionally oriented } \\
\text { text in oral or written forms; } \\
\text { - often evaluates inadequately; is } \\
\text { too critical; is inclined to spot } \\
\text { errors and correct them; } \\
\text { - has some difficulties in changing } \\
\text { tactics and strategies in } \\
\text { professional communication if } \\
\text { necessary; } \\
\text { - needs some teacher's / peers' } \\
\text { support. }\end{array}$ & $\begin{array}{l}\text { A student } \\
\text { - has sufficient difficulties in } \\
\text { defining and understanding } \\
\text { the goals (using their } \\
\text { language learning style at } \\
\text { their language proficiency } \\
\text { level) in an ongoing } \\
\text { communicative situation as } \\
\text { well as in the "zone of } \\
\text { proximal development"; } \\
\text { - with considerable difficulties } \\
\text { thinks through, plans and } \\
\text { identifies the program steps; } \\
\text { minimally deploys the } \\
\text { English professionally } \\
\text { oriented text in oral or } \\
\text { written forms; } \\
\text { - has sufficient difficulties in } \\
\text { self-evaluation; is not } \\
\text { critical; does not notice } \\
\text { errors and does not correct } \\
\text { them; } \\
\text { - has substantial difficulties in } \\
\text { changing tactics and } \\
\text { strategies in the professional } \\
\text { communication if necessary; } \\
\text { - needs substantial teacher's / } \\
\text { peers' support. }\end{array}$ \\
\hline
\end{tabular}


According to the research findings (Schunk \& Swartz, 1993), the rise of the level of learners' regulation leads to the enhancement of the learning outcomes of these students, which makes it possible to assume that such tendency can also be observed in the differentiated ESP instruction. To raise the level of self-regulation in ESP learning both teachers and students must understand the algorithm of actions to be taken. For this purpose, a checklist may be used as a cognitive tool which employs logically organised and detailed information to enhance the results of training (Fletcher et al., 2018, p. 11). Using three phases of Zimmerman \& Campillo's model (2003) of self-regulation within linked and interdependent cognition, metacognition, motivation, emotion and behaviour regulatory areas, a universal self-regulation checklist can be suggested in the context of differentiated ESP instruction. It consists of:

(1) The preparatory phase:

- understanding the task to be performed, relating it to the dominant or preferable language learning style and English language proficiency level (cognitive area);

- defining real short and long-term goals within the real time limits; correlating goals with outcomes (products); outlining the algorithm of performance of tasks defining their priorities (the most important and the most difficult ones; important and difficult ones; important and easy ones) (metacognitive area);

- focus on professional content of the task in a particular communicative situation (motivation area);

- orientation on the positive attitude to the task performance (emotion area);

- awareness of the goals and program of task performance (behaviour area).

\section{(2) The performance phase:}

- choosing appropriate cognitive (analytical or synthetical; deductive or inductive, etc.) strategies according to the language learning style (cognitive area);

- monitoring the progress of the task performance and controlling the time limits (metacognitive area);

- activating students' interest through emphasising the relevance of the task to the future profession; using different resources (motivation area);

- thinking positively, non-judgmentally, switching from negative emotions to a rewarding perspective (emotion area);

- applying efforts to completing the task or making changes in the goals and algorithm of performance if necessary (behaviour area).

(3) The reflection phase:

- analysing and evaluating the final product according to the criteria (cognitive area);

- defining the drawbacks and the ways of avoiding them (metacognitive area);

- determining the most interesting points of the task (motivation area);

- creating positive attitude to ESP learning (emotion area);

- correcting mistakes, matching goals and outcome (behaviour area).

As the differentiated ESP instruction focuses on individuals who are joined into homogeneous or heterogeneous groups (pairs, three-, four-, five-member groups), socially shared regulation and co-regulation take place in the learning process. The same three phases of Zimmerman's (2003) model of self-regulation within interdependent cognition, metacognition, motivation, emotion and behaviour regulatory areas can be used for creating the universal socially shared regulation and co-regulation checklist in differentiated ESP instruction. It involves:

(1) The preparatory phase:

- understanding the task to be performed, correlating it with students' dominant or preferable language learning style and English language proficiency level (cognitive area);

- defining individual goals and strategic group goals within time limits; outlining the algorithm of the actions of an individual and the whole group / team to have maximum contribution of each individual; delegating the roles and tasks with consideration of the strengths of each participant (metacognitive area);

- focus on interesting professional content of the task in a particular communicative situation (motivation);

- orientation to the positive attitude to the task of each member of the group / team (emotion area);

- awareness of the goals and program of the task performance; taking the responsibility for the task (behaviour area). 
(2) The performance phase:

- synchronising the actions in the group paying attention to the use of appropriate cognitive strategies within the language learning style (cognitive area);

- monitoring the progress of the task performance and controlling the time limits in the group (metacognitive area);

- understanding the relevance of the group and individual task to the future profession; use of different resources (motivation area);

- engagement in positive communication with other members of the group (emotion area);

- applying efforts to completing the task by different participants or making changes in the goals and algorithm of performance if necessary (behaviour area).

(3) The reflection phase:

- analysing and evaluating the final product / interaction on the individual and group level according to the criteria (cognitive area);

- defining the drawbacks and ways of avoiding them on the individual and group level (metacognitive area);

- determining the most interesting points of the task (motivation area);

- creating positive attitude to the task performed (emotion area);

- correcting mistakes, matching goals and outcome on the individual and group level (behaviour area).

Based on the results of our study of self-regulation in listening, speaking, reading, and writing, we outlined recommendations. While reading IT students can use visual scaffolding (schemes, mind maps, word clouds, taking notes for better understanding, etc.), define the main parts of the text, review information, make up questions, write abstracts or reviews, render texts, use checklists, analyse mistakes in the test. While listening the students can use audio scaffolding (sub-titles, schemes, mind maps, word clouds, taking notes for better understanding; slowing down the pace), listen to the same text or parts of it several times, write summaries, render texts, use checklists. While writing we suggest text planning and structuring, applying visual scaffolding (schemes, mind maps, word clouds, taking notes), revising and editing a written text; using checklists. To improve the students' self-regulation in speaking students can perform text planning and structuring, use visual scaffolding (schemes, mind maps, word clouds), analyse mistakes in a recorded text.

\section{Limitations}

This study was devoted to self-regulation as an aspect of learner's language learning style in differentiated instruction. The research had certain limitations, since it was conducted in context ESP instruction only. However, in our opinion, its results can be used in the study of other disciplines at technical university when the development of students' self-regulation is in focus.

\section{Conclusions}

In conclusion, it is possible to say that the regulation aspect of the learners' language learning style influences the productivity of ESP learning. Survey of IT learners for determining the self-regulation levels showed that most of them had a medium level of self-regulation. The described levels interpreted for ESP learning may allow teachers to provide necessary assistance to students at different stages of training in the process of development of professional communicative competence. To improve the level of learner's regulation, both teachers and students need to understand the algorithm of regulation actions that can be presented as a checklist. Since learning can be conducted individually, in pairs, teams and groups, various specifics of students' regulation in ESP study was reflected in checklists for self-regulation, socially shared regulation and co-regulation. Based on the results of our study of self-regulation in listening, speaking, reading, and writing, recommendations were outlined for organising the differentiated ESP instruction. Thus, efficient development of language skills depends on the learner's regulation which involves being more flexible and adaptable, more organised, self-disciplined, motivated, able to control emotions.

\section{References:}

Creswell, J.W. (2014). Research Design: Qualitative, Quantitative and Mixed Methods Approaches. Sage, Los Angeles.

Derkach, T. (2018). Preferred Learning Styles of Students Majoring in Chemistry, Pharmacy, Technology and Design. Advanced Education, 9, 55-61. doi.org/10.20535/2410-8286.131078

Dörnyei, Z. (2005). The Psychology of the Language Learner: Individual Differences in Second Language Acquisition. London and New York: Lawrence Erlbaum Associates.

Dörnyei, Z. \& Ryan, S. (2015). The Psychology of the language learner revisited. New York, N. Y.: Routledge. doi:10.4324/9781315779553 
Fletcher, K. A., Bedwell, W. L., Frick, S. E. \& Telford, B. N. (2018). Enhancing training with well-designed Checklists. International Journal of Training and Development, 22(4), 289-300. doi:10.1111/ijtd.12139

Guild, P. B. \& Garger, S. (1998). Marching to Different Drummers. 2nd ed. Alexandria, Va.: Association for Supervision and Curriculum Development.

Hadwin, A., Järvelä, S., and Miller, M. (2018). Self-regulation, Co-regulation, and Shared Regulation in Collaborative Learning Environments. In D. H. Schunk \& J. A. Greene, Handbook of Self-Regulation of Learning and Performance (2nd ed., pp. 83106). New York: Routledge. doi:10.4324/9781315697048-6

Hoyle, R. H. \& Dent, A. L. (2018). Developmental trajectories of skills and abilities relevant for self-regulation of learning and performance. In D. H. Schunk \& J. A. Greene, Handbook of Self-Regulation of Learning and Performance (2nd ed., pp. 4963) New York: Routledge. doi:10.4324/9781315697048-4

Kaplan, J., de Montalembert, M., Laurent, P., \& Fenouillet, F. (2017). ERICA - an instrument to measure individual and collective regulation of learning. European Review of Applied Psychology, 67(2), 79-89. doi:10.1016/j.erap.2017.01.001

Macaro, E. (2001). Learning strategies in foreign and second language classrooms. London: Continuum.

Mahmoodi, M. H., Kalantarib, B., \& Ghaslanic, R. (2014). Self-Regulated Learning (SRL), Motivation and Language Achievement of Iranian EFL Learners. Procedia - Social and Behavioral Sciences, 98, 1062-1068. doi:10.1016/j.sbspro.2014.03.517

Morosanova, V. I. \& Bondarenko, I. N. (2015). Diagnostika samoregulyatsii cheloveka [Diagnosis of human self-regulation]. Moskva: Kogito-Tsentr.

Nilson, L. B. (2013). Creating self-regulated learners' strategies to strengthen students' self-awareness and learning skills. Sterling Stylus Publ.

Pintrich, P. R. (2000). The role of goal orientation in self-regulated learning. In M. Boekaerts, P. R. Pintrich, and M. Zeidner, Handbook of Self-Regulation (pp. 452-502). San Diego, CA: Academic Press.

Saienko, N. (2017). Cognitive development of students in foreign language acquisition. Advanced Education, 7, 4-8. doi: $10.20535 / 2410-8286.77570$

Schunk, D. H., \& Swartz, C. W. (1993). Goals and progress feedback: effects on self-efficacy and writing achievement. Contemporary Educational Psychology, 18, 337-354. doi:10.1006/ceps.1993.1024

Synekop, O. (2018). Cognitive aspect of learning style in differentiated esp instruction for the future it specialists. Advanced Education, 10, 40-47. doi:10.20535/2410-8286.151271

Tezci, E., Sezer, F., Aktan, S. \& Gurgan, U. (2016). Do lifestyles shape self-regulated learning strategies? Eurasian Journal of Educational Research, 65, 239-258. doi:10.14689/ejer.2016.65.14

Thiede, K. W. and Bruin, A. B. H. de (2018). Self-regulated learning in reading. In D. H. Schunk \& J. A. Greene, Handbook of SelfRegulation of Learning and Performance (2nd ed., pp. 124-137). New York: Routledge. doi:10.4324/9781315697048-8

Vermunt, J. D. (1998). The regulation of constructive leaming processes. British Journal of Educational Psychology, 68, 149-171. doi:10.1111/j.2044-8279.1998.tb01281.x

Zimmerman, B. J., \& Campillo, M. (2003). Motivating self-regulated problem solvers. In J. E. Davidson \& R. Sternberg (Eds.), The Psychology of Problem Solving (pp.233-262). New York: Cambridge University Press. doi:10.1017/cbo9780511615771.009

Zimmerman, B. J. (2001). Theories of self-regulated learning and academic achievement: an overview and analysis. In B. J. Zimmerman \& D. H. Schunk (Eds.), Self-regulated learning and academic achievement: Theoretical perspectives (2nd ed., pp. 1-37). Mahwah, NJ: Erlbaum.

Received: January 29, 2020

Accepted: April 30, 2020 